\section{Push to decarbonize cities after Paris talks}

As the United Nations climate summit in Paris draws to a close, we suggest that cities should be a focus of action against climate change (see also D. G. Victor and J. P. Leape Nature 527, 439-441; 2015). Covering just $3 \%$ of Earth's surface but housing more than half of its population, they account for $70 \%$ of global energy demands.

Cities are already ahead of nations on climate policy. Initiatives such as C40 Cities (www.c40.org) and the World Mayors Council on Climate Change (go.nature.com/yyqjre) help urban centres to integrate climate objectives into current policy and long-term planning. The Cities for Climate Protection campaign run by the global cities network ICLEI, for example, has prevented emissions equivalent to some 54 million tonnes of carbon dioxide from more than 1,000 cities (see www.iclei.org).

We shall still have to cope with factors that affect city infrastructures and supply chains, such as rising sea levels, accelerating migration from rural to urban areas, and more frequent and extreme weather events. Fundamental changes are needed in the way that we build and manage the urban environment (see go.nature.com/q61pq5). Matthew Agarwala ${ }^{\star}$ London School of Economics and Political Science, UK.

m.k.agarwala@lse.ac.uk ${ }^{*}$ On behalf of 7 correspondents (see go.nature.com/du4zld for full list).

\section{Continental targets for EU conservation}

The European Union is currently evaluating the relevance of its environmental policies (see go.nature.com/vkm9r7). We have contributed to this by reviewing the 1,448 projects that were funded from 1992 to 2013 to the tune of $€ 3$ billion (US $\$ 3.2$ billion) by the EU under LIFE Nature, its main financial tool for conservation programmes.

We find that a disproportionate amount of funding is directed towards species that are not under global threat and/or to regions of low conservation priority (unpublished data; see also go.nature.com/omfvfn). In our view, the EU's conservation programme would benefit from more strategic planning and more flexibility when it comes to setting conservation priorities. Fixed lists, such as those setting conservation priorities in EU directives, can rapidly become outdated.

More funding is not necessarily the answer (see, by contrast, V. Kati Conserv. Biol. 29, 260-270; 2015). We recommend that funds should be allocated according to continental and global needs, overriding national government interests. This would also help to prevent unnecessary duplication of efforts in different countries. In our view, continental conservation objectives, such as the EU's Biodiversity Strategy for 2020, need continental-scale plans. Virgilio Hermoso ${ }^{*}$ Catalonia Forest Sciences Centre (CTFC), Solsona, Spain.

virgilio.hermoso@gmail.com ${ }^{\star}$ On behalf of 4 correspondents (see go.nature.com/sggtgffor full list).

\section{Citizen scientists can aid diagnostics}

Citizen scientists are an underrated source of observations on medical conditions. They frequently offer researchers a head start in the hunt for biomarkers (see, for example, the tentative identification of volatile indicators of early Parkinson's disease: go.nature.com/wggoss).

The precision and highthroughput capability of analytical technology drives most advances in clinical diagnostics (L. M. McShane et al. Nature 502, 317-320;
2013). Analytical science and its subdiscipline metabolomics (the study of chemical fingerprints left by cellular processes) are also crucial for guiding clinical decisions (see go.nature.com/ $18 \mathrm{pcde}$ ). These tools are set to be valuable for investigating and tapping into citizen scientists' previously unreported medical phenomena.

Nicholas J. W. Rattray*

SYNBIOCHEM, University of

Manchester, UK.

nicholas.rattray@manchester.ac.uk ${ }^{*}$ On behalf of 5 correspondents (see go.nature.com/uy $7 w 5$ for full list).

\section{Europe must fund social sciences}

The peer-reviewed Social Impact Open Repository (SIOR) was launched by the European Commission earlier this year to evaluate the social benefits of research (www.ub.edu/sior). Its success is an argument against the commission's plans to eliminate the social sciences and humanities component from its Horizon 2020 research-funding programme.

Contributors of evidence of social impact to SIOR include the Informal Economy Monitoring Study of the WIEGO project (Women in Informal Employment: Globalizing and Organizing) based at Harvard University in Massachusetts. The project has helped women to organize labour, gain recognition and defend their rights in ten cities in Africa, Asia and Latin America (see www.wiego.org). Spain's Atapuerca project has enhanced economic growth and cultural development in the region where the first human bones were discovered (see E. Carbonell et al. Nature 452, 465-469; 2008). And the ALACs project, which promotes citizenship through its Advocacy and Legal Advice Centres, has helped citizens to tackle corruption in the Balkan and Caucasus areas (see go.nature.com/qnmefy).

The open repository scores research on metrics such as social improvement, transferability to diverse populations or social contexts, and sustainability. SIOR data are also used to back research proposals.

Ramon Flecha, Marta SolerGallart University of Barcelona, Spain.

Teresa Sordé University Autonoma of Barcelona, Spain. marta.soler@ub.edu

\section{Science festivals preach to the choir}

Science festivals are designed to expand the public's interest in science, but we find that this genre of science communication appeals mainly to a select clientele.

As part of our ongoing evaluation to determine how such activities might be improved (E. Jensen and N. Buckley Public Underst. Sci. 23, 557-573; 2014 and E. Jensen J. Sci. Commun. 14, Y05; 2015), we found that attendees at UK science festivals are more highly educated and economically advantaged than most of the population. Attendees are also disproportionately pro-science, and tend to be highly engaged in a wide range of cultural events.

This pattern reinforces existing sociocultural divides by benefiting privileged groups. Given their large investment in science communication, we recommend that scientists, universities and governments demand higher standards of inclusivity and use evidencebased practices at science festivals.

Eric A. Jensen University of Warwick, Coventry, UK.

Eric B. Kennedy Arizona State

University, Tempe, Arizona, USA. Monae Verbeke Institute for Learning Innovation, Portland, Oregon, USA.

ericbkennedy@asu.edu 